\title{
Rental Housing Markets, the Incidence and Duration of Vacancy, and the Natural Vacancy Rate
}

by

Stuart A. Gabriel and Frank E. Nothaft

June 1999

Lusk Chair in Real Estate and Director, USC Lusk Center for Real Estate, Marshall School of Business and School of Policy, Planning, and Development, Los Angeles, California, 900891421 and Deputy Chief Economist, Department of Housing Economics and Financial Research, Freddie Mac, McLean, Virginia 22102-3107, respectively.

The authors are grateful to the Real Estate Research Institute for research financial support. The authors further wish to thank David Kogut and Doug Carson for capable research assistance, Frank Ptacek and Steve Henderson of the Bureau of Labor Statistics for many discussions regarding the CPI housing sample, and Bill Wheaton for comments on the rental-adjustment process. The views expressed are those of the authors and do not necessarily reflect those of Freddie Mac or the Bureau of Labor Statistics. Earlier versions of this paper were presented at the Financial Management Association annual meeting, 1998 AREUEA annual meeting, and the 1999 AREUEA-AsRES International Conference. 


\title{
Rental Housing Markets, the Incidence and Duration of Vacancy, and the Natural Vacancy Rate
}

\begin{abstract}
New intermetropolitan and time-series data from the BLS are used to derive and model the incidence and the duration of rental vacancies and to assess the importance of those indicators to the price adjustment mechanism for rental housing. Research findings indicate that the duration of vacancy varies with measures of MSA housing costs and housing stock heterogeneity; in contrast, the incidence of vacancy varies directly with measures of population mobility, presence of public housing units, and population growth. Results support a more general specification of rental price adjustment in which the rate of real rent change reflects deviations in observed vacancy incidence and duration from their equilibrium levels. Based on this innovation, the research provides new estimates of equilibrium vacancy rates for a large set of metropolitan areas over the 1987-1996 period.
\end{abstract}

JEL Classification: R21, R31 


\section{Introduction}

In the wake of ongoing and sizable fluctuations in rental housing market activity, analysts, investors, and lenders alike have sought improved methods by which to evaluate risk and return to investment in residential properties. To that end, academic analyses often have focused on the role of equilibrium vacancy rates in determination of the rental price adjustment mechanism (see, for example, Blank and Winnick [1953], Rosen and Smith [1984], Gabriel and Nothaft [1988], Mueller [1991], Wheaton and Torto [1994], and Belsky and Goodman [1996]). ${ }^{1,2}$ Empirical research has shown that fluctuations in residential rents are driven by deviations in observed vacancy rates from equilibrium levels; in many metropolitan areas, observed vacancy rates currently appear to be well in excess of equilibrium levels, suggesting damped rates of return to investors and concomitant risks to multifamily lending and construction. To date, however, researchers have yet to glean insights into rental market adjustments associated with the decomposition of vacancy into its incidence and duration components. As is well appreciated, an analogous decomposition of unemployment rates has proven critical to assessment of the source and policy significance of fluctuations in labor market activity.

As in the case of unemployment rates, residential vacancy rates may be expressed as the product of the incidence of vacancy and the duration of vacancy (see, for example, Leighton and Mincer [1982] and Johnson and Layard [1986]). Incidence of vacancy is the probability that a

\footnotetext{
${ }^{1}$ Analogous to its counterpart in labor markets, the equilibrium or "natural" vacancy rate is defined as that rate associated with a constant level of real rents; accordingly, increases (decreases) in real rents over time reflect excess demand (supply) for rental housing as indicated by observed vacancy rates below (in excess of) their equilibrium levels.

${ }^{2}$ Wheaton and Torto [1994] expand on the standard rental market price adjustment mechanism to emphasize the role of tenant mobility in the determination of rent levels.
} 
housing unit becomes vacant, whereas duration of vacancy is the length of time that a unit remains in vacant status. ${ }^{3}$ For particular rental property types, the incidence measure is useful in indicating variation over time and across metropolitan areas in the proportion of the stock that experiences a spell of vacancy, whereas the duration measure provides insight into systematic variations over time and space in the length of time that a typical unit remains vacant. ${ }^{4}$ Phenomena that cause the incidence of vacancy to be higher or the duration of vacancy to be longer will lead to a higher vacancy rate. Decomposition of vacancy rates into their incidence and duration components accordingly yields new information as to the source of fluctuations in the overall indicator; such information may be of critical importance to developers, lenders, regulators, and others requiring analyses of particular rental markets. Real estate development and policy implications also vary critically across these vacancy categories. For example, higher levels of vacancy incidence may reflect a voluntary, profit- and utilitymaximizing turnover of stock in rental housing markets, whereas higher levels of vacancy duration may reflect structural mismatches between the characteristics or locations of units available for rent and the demands of potential tenants. Data series on vacancy incidence and duration would permit evaluation of systematic determinants of those vacancy components as well as assessment of their separate contributions to the price adjustment mechanism for rental housing.

\footnotetext{
${ }^{3}$ The Bureau of the Census defines a vacant unit as an unoccupied unit that is available for sale or rent. Accordingly, a rental vacancy duration starts when a unit becomes vacant (either because an occupant moves out of an existing unit or because the unit enters the market) and ends when the unit ceases to be for rent (either because someone rents the unit or because it is removed from the market).

${ }^{4}$ Alternatively put, the annual average duration of vacancy can be viewed as the nominal vacancy rate normalized by the annual incidence of vacancy. To the extent that the incidence of vacancy is stable, the nominal vacancy rate and the duration of vacancy become equivalent indicators of a given rental housing market. As is indicated in our empirical estimates, however, the incidence of rental vacancies exhibits considerable cross-MSA variation.
} 
Unfortunately, there has been no previous study that has focused on the measurement or contribution of the incidence and the duration of vacancy to observed vacancy patterns or rental market adjustments among U.S. metropolitan areas. ${ }^{5}$ The void can be attributed in part to a lack of data appropriate to the decomposition of the vacancy rate into its duration and incidence components. For example, the American Housing Survey (AHS) collects virtually no information on the incidence or duration of vacancy between rental stock survey dates, and the estimation of duration is truncated because the termination date of the vacancy is never observed. ${ }^{6}$ As is evident, the ideal data set would survey individual rental units with a high frequency and also would include information on the occupancy status of the unit over the period of observation.

This paper provides derivation and analytical modeling of the duration and incidence of vacancy as well as empirical assessment of the contribution of those factors to the functioning of rental housing markets. In so doing, the study applies heretofore underutilized data from the Bureau of Labor Statistics (BLS) to compute the rate, incidence and duration of rental vacancies for major MSAs in the United States. The study indicates the extent to which variation in residential vacancy rates across metropolitan areas and over time is due to differences in vacancy incidence, vacancy duration, or both. The research then undertakes econometric evaluation of the incidence and duration measures and provides new insights regarding the determinants of those indicators. Finally, the incidence and duration measures also are

\footnotetext{
${ }^{5}$ In an early study using data from the Housing Assistance Supply Experiment, Rydell [1978] estimates the duration of vacancy and the turnover of units for housing in St. Joseph County and Brown County, Indiana.

${ }^{6}$ Rental apartments included in the American Housing Survey are revisited biennially by survey takers, and include information on the duration of vacancy only for those units vacant as of the survey date. The survey contains no information on the inter-survey incidence or duration of vacancy for those units occupied as of the survey date.
} 
employed to compute new equilibrium rental vacancy rates and to evaluate the price adjustment mechanism for rental housing.

Examination of the BLS data indicates sizable and significant variation in the incidence and the duration of rental vacancies across metropolitan areas and over the rental housing cycle. For instance, New York City has the lowest vacancy measures, as well as the lowest incidence and duration of vacancy; whereas Houston has relatively high levels of all three measures. Comparison of duration estimates with data contained in the American Housing Survey lends credence to the research approach and demonstrates the apparent undercounting of short spells of vacancy duration by more traditional rental vacancy datasets.

Econometric models indicate that the average duration of vacancy varies directly with measures of potential tenant search costs and in areas of higher median housing costs. Accordingly, mechanisms to enhance the flow of information on available units could go some distance toward lowering search costs and improving the efficiency of rental market allocations. In contrast, the incidence of vacancy varies positively with measures of population mobility, the presence of public housing units, and population growth. Vacancy incidence reflects in part frictions in the rental housing market--an anticipated and desired consequence of household moves that serve to enhance the efficiency of housing allocations. The analysis further rejects the restricted empirical formulation of the rental price adjustment mechanism prevalent in the literature in favor of a more general specification in which the rate of change in real rents reflects deviations in observed vacancy incidence and duration from their equilibrium levels. Based on this innovation, the research further provides new estimates of equilibrium vacancy rates for a large set of metropolitan areas over the 1987-1996 period. Overall, findings lend credence to model specification and provide new insights regarding the importance of vacancy incidence and duration in the analysis of the rental housing markets. 
The plan of the paper is as follows. The following section describes the data and reports on the decomposition of metropolitan area vacancy rates into their incidence and duration components. Section III makes explicit the role of the incidence and duration of vacancy in the price adjustment mechanism for rental housing. Section IV reports on econometric evaluation of the determinants of cross-sectional and intertemporal variation in the incidence and duration of rental vacancies and the use of those measures to derive new estimates of the rental price adjustment mechanism. Finally, section V discusses conclusions and policy implications of the research.

\section{The Incidence and the Duration of Rental Vacancies}

2.1 The CPI Housing Sample. The Consumer Price Index (CPI) housing sample is the source of information on changes in the price of housing services for the CPI's two principle shelter indexes--the residential rent index and the owners' equivalent rent index. The CPI housing sample is a stratified cluster sample of approximately 40,000 rental units and 20,000 owner units. $^{7}$ The overall sample is divided into six panels with rental units surveyed every six months, resulting in two data collections per year per apartment in the sample. ${ }^{8}$

In any given month, the BLS field representatives visit that month's housing panel and gather information on, among other items, the tenure status of the dwelling unit (owner or rental), current occupancy status (vacant or occupied), duration in months of occupancy (if

\footnotetext{
${ }^{7}$ The CPI housing sample used in this paper was initiated in January 1987 at the time of the previous revision of the overall index. For additional information, see U.S. Department of Labor, BLS Handbook of Methods, Bulletin 2285, "Chapter 19: The Consumer Price Index" [1988]. In order to ensure that the CPI housing sample remains current, the BLS augments the dataset based on building permit data obtained from the Census Bureau and from canvassing of areas not requiring building permits.

${ }^{8}$ Thus there is a "January-July" rental panel which is surveyed in each of those months, a "FebruaryAugust" panel, a "March-September" panel, and so on. Note, however, that only half of the owner units are surveyed in each of the panel survey months, resulting in the collection of owner data only once during the year (e.g., half of the owner units in the "January - July" panel are surveyed in January and the other half in July).
} 
occupied), and, for rental units, the rent. The resulting dataset is well suited to the analysis of vacancy, including the estimation of the incidence and the duration of vacancy, because of its high sampling frequency and the detail of information collected over the between-survey period. The analysis undertaken in this paper uses the CPI housing sample over the January 1987 to December 1996 period.

In general, the rental vacancy rates by metropolitan statistical area (MSA) as estimated from the BLS dataset are comparable to the rates obtained from the vacancy survey conducted by the Census Bureau. Table 1 reports on annual vacancy rates in ten metropolitan areas common to the BLS and Census datasets over the 1987-93 period; the "H" and "L" indicate years in which both datasets register the "highest" and "lowest" vacancy rates during that time period. Perhaps most striking is the fact that the trends in vacancy rates are fairly similar over time and across metropolitan areas in the two datasets, especially for the larger markets. In five of the markets, the peaks and troughs of the vacancy rate fluctuations coincide. A ranking of the areas by mean vacancy rate gives a similar ordering: the Tampa-St. Petersburg-Clearwater, Atlanta, and Nashville MSAs have the highest mean vacancy rates according to both datasets, whereas the Minneapolis-St. Paul and New York metropolitan areas have the lowest mean rates. Furthermore, the mean vacancy rates from the two datasets are generally within a standard deviation of one another.

2.2 Derivation of the Incidence and Duration Measures. The observed vacancy rate fails to indicate whether a sizable proportion of the rental stock experiences a short spell of vacancy (on average) or whether a relatively small proportion of the rental stock bears a sizable portion of the vacancy burden by way of relatively long spells of vacancy. ${ }^{9}$ The ability to differentiate

\footnotetext{
${ }^{9}$ For example, an equivalent vacancy rate would be computed for a particular period when a certain proportion of the rental housing stock is vacant for an average of one month or when only a quarter of that proportion is vacant for an average period of four months.
} 
between these two possibilities allows for more complete explanations of intertemporal and intermetropolitan variation in nominal vacancy rates and accordingly facilitates the analysis of the effects of governmental policies or economic forces on the rental housing market.

The decomposition of the vacancy rate into its incidence and duration components can be illustrated as follows. Let $\mathrm{M}_{\mathrm{i}}$ represent the number of months during a given period, say, one year, that the $\mathrm{i}^{\text {th }}$ apartment is vacant for rent; $\mathrm{V}_{\mathrm{i}}$ the number of spells of vacancy entered into by the $i^{\text {th }}$ rental unit that year $\left(M_{i}\right.$ and $V_{i}$ will equal zero for an apartment occupied all year long); and $\mathrm{H}$ is the rental housing stock each month during the year (vacant and occupied). Then the market vacancy rate for the year is

$$
\frac{\sum_{i} M_{i}}{12 * H}
$$

while the incidence (or likelihood) of an apartment being vacant at some time during the year is

$$
\frac{\sum_{i} V_{i}}{H}
$$

and the average duration of a vacancy spell is (in months)

$$
\frac{\sum_{i} M_{i}}{\sum_{i} V_{i}}
$$

or, expressing vacancy duration as a fraction of a year,

$$
\frac{\sum_{i} M_{i}}{12 * \sum_{i} V_{i}}
$$

Clearly, the vacancy rate is the product of incidence and average duration:

$$
\frac{\sum_{i} M_{i}}{12 * H}=\frac{\sum_{i} V_{i}}{H} * \frac{\sum_{i} M_{i}}{12 * \sum_{i} V_{i}}
$$

While this derivation assumes, for simplicity, a constant rental housing stock over the period, it is straightforward to extend the analysis to incorporate additions or deletions from the rental 
stock. For instance, defining $\mathrm{H}_{\mathrm{i}}$ to be the number of months during the year that the $\mathrm{i}^{\text {th }}$ dwelling unit is in the rental stock (either as an occupied unit or as a vacant apartment for rent), then the average monthly rental stock, $\bar{H}$, is $\sum_{i} H_{i} / 12$, and the above decomposition can be rewritten as

$$
\frac{\sum_{i} M_{i}}{12 * \bar{H}}=\frac{\sum_{i} V_{i}}{\bar{H}} * \frac{\sum_{i} M_{i}}{12 * \sum_{i} V_{i}}
$$

Because of the high survey frequency of the CPI rental housing sample (every six months) and the information collected on length of occupancy, the number of spells of vacancy, $\mathrm{V}_{\mathrm{i}}$, can be tabulated for each rental apartment. ${ }^{10}$ Once the vacancy spells are tabulated and the average rental housing stock computed, then incidence is the resulting quotient. Average duration can then be computed as the vacancy rate divided by the incidence, as indicated in the above decomposition.

The calculation of vacancy rate, incidence, and duration for the CPI housing sample over the various observation period lengths is shown in Table 2. The rate at which incidence and duration of vacancy increase as the period of observation lengthens indicates the degree of persistence of vacancy or its converse, the degree of turnover among the vacant units. The degree of persistence observed in the data may be due to positive serial correlation in the

\footnotetext{
${ }^{10}$ The tabulation method is shown in Appendixes A and B. Appendix A illustrates the method when the observation period is six months (two consecutive surveys of rental units) and the apartments are in the rental stock at both survey dates. In this situation there are five cases, only the first of which represents a case where there is no spell of vacancy. In the first case, the apartment is continually occupied (because the unit is occupied at both survey dates, and because the tenant reported living there over the six month period as of the second enumeration). Each of the remaining cases reflect the apartment having a spell of vacancy at some time over the six month period. For instance, the second row depicts the case where the unit is occupied at both survey dates, but the tenant at the second date reported residing in the apartment less than six months; here we assume that the apartment experienced a spell of vacancy when the tenant turnover occurred. Appendix B illustrates the method for a twelve-month observation period (three consecutive surveys of rental units); this periodicity has thirteen alternative cases.
} 
probability of a particular rental unit experiencing vacancy, or to heterogeneity in the probability of experiencing vacancy across units, or both.

The analysis is based on the first five survey dates of each panel in the dataset. For example, for the January - July panel, the survey dates are January 1987, 1988, and 1989, and July 1987 and 1988. An observation period length of six months is shown in the first four rows, a twelve-month length in the next two rows, and a twenty-four month interval in the bottom row. $^{11}$

Table 2 reveals several interesting findings. First, as the vacancy rate edged up over the first four six-month periods, incidence changed very little; the increase in vacancy rates was largely attributable to phenomena that increased the duration of vacancy, not the frequency of vacancy. Second, average duration estimates generally lie between 1.5 to 2 months, which is an intuitively plausible range. Third, there is a great deal of tenant mobility and apartment turnover; over six-month intervals approximately 30 percent of apartments experience a vacancy spell, or, in other words, 70 percent of units remain continuously occupied (right-most column). The proportion of apartments continuously occupied declines as the observationperiod length increases, as one might expect, but the decline is not as rapid as indicated in the six-month estimates. For instance, if there was "complete turnover" in those units experiencing a vacancy, so that those apartments vacant in one six-month interval are never vacant in any other six-month interval over our total observation period, then there would not be any units continuously occupied through a twenty-four month interval. If "complete persistence" in

\footnotetext{
${ }^{11}$ The first period refers to the dates of the first two surveys of an apartment (e.g., January and July 1987), the second period to the second and third survey dates (e.g., July 1987 and January 1988), and so on. The fifth row represents calculations over the first twelve-month period of each panel and, as such, should yield a vacancy rate between the values computed for the first two rows, as it does. Finally, the bottom row covers the first twenty-four months of each panel, and yields a vacancy rate between the high and low of the individual six-month periods, as it should.
} 
vacancy is defined to mean that it is the same group of apartments that experience vacancy spells over and over, then the proportion continuously occupied over twenty-four months would remain at .70 . Since the actual figure, .40 , is between these two extremes, it indicates that a significant degree of persistence coexists with a great deal of turnover. In other words, some rental units are more susceptible to vacancy spells, probably because of local economic and demographic characteristics, as well as characteristics of the apartments themselves.

While the estimates of duration are similar by observation-period length, the duration estimates do tend to be somewhat higher as interval length increases. ${ }^{12}$ Any bias that this introduces into the incidence calculation is diminished by increasing the observation-period length. Thus, the duration estimates in the fifth and sixth rows of Table 2 are similar to the estimate in the last row. In the remainder of this paper, we compute the incidence and the duration of vacancy using twelve month intervals.

2.3 Variation in Incidence and Duration of Vacancy by Metropolitan Area Market. The stock of rental housing is dynamic. While the large majority of apartments remain in the rental stock for extended periods of time, some units are added to the stock as previously owner-occupied units become available for rent or because new units are constructed, whereas other units are removed from the stock (either through conversion to owner use or due to demolition). Apartments that are removed from the rental stock have noticeably higher vacancy rates and duration, consistent with the notion that units withdrawn from the rental stock may be subpar and/or lack the physical or locational characteristics demanded by potential tenants. ${ }^{13}$ The following analysis includes units that are in the rental stock for three consecutive surveys; those

\footnotetext{
${ }^{12}$ This may reflect the method used to count vacancy spells, in which we assume that an apartment that is vacant at its initial observation is a new spell of vacancy, whereas the spell began at an earlier date.
} 
units provide a more complete description of ongoing rental market conditions in the various markets.

Table 3 illustrates the decomposition of vacancy rates into the incidence of vacancy and the duration of vacancy for five markets over three different time periods. As is evident, the BLS data indicate substantial variation in the incidence and duration of vacancy across metropolitan areas and over time. Over the 1987 - 1994 period, New York City rental housing markets were characterized by the lowest vacancy rates, as well as the lowest incidence and duration of vacancy estimates. Vacancy rates, incidence, and duration trended down significantly in Houston during that period; nonetheless, that metropolitan area was at the high end of all three measures.

Table 4 presents estimates of the distribution of the duration of vacancy from the AHS and BLS datasets. The AHS collects duration data only for units vacant as of the survey date; a comparable tabulation from BLS data is shown in the second column. The distribution of duration is similar in the two datasets, although the AHS reports more units with long vacancy durations (24 months or more) and higher vacancy rates. The right-most column shows the duration of vacancy spells over the prior year, including the duration (to date) of currently vacant apartments and completed vacancy spells over the prior twelve-month interval. Clearly, short spells of duration are undercounted if one uses the AHS dataset, illustrating the problems of using the AHS to decompose vacancy rates into their incidence and duration components. Duration estimates derived from the AHS will be too high, and estimates of incidence too low, when compared with actual behavior in the rental housing market.

\footnotetext{
${ }^{13}$ Appendix $\mathrm{C}$ provides calculations of the vacancy rate, incidence and duration for the portion of the rental stock that remains in rental use and for the portion that is withdrawn from the stock for five major markets.
} 


\section{Incidence, Duration, and Equilibrium Vacancy Rates}

The decomposition of the vacancy rate makes possible assessment of the explicit role of incidence and duration of vacancies in the price adjustment mechanism for rental housing. Indeed, the empirical literature in labor economics has followed a similar vein to garner additional insights regarding the determinants of unemployment (for example, see Leighton and Mincer [1982]). A starting point is the standard stock-flow model, whereby the stock of rental housing in a particular metropolitan area is assumed fixed in the short-run but evolves over time in response to changes in the expected rate of return to investments in rental properties. Further, it is assumed that each standardized unit of housing stock yields a unit of housing services in each period. The intersection of supply and demand for rental housing services yields a level of apartment rents as well as a short-run stock of vacant units.

Excess demand for units—-due to factors which serve to push the observed incidence or duration of rental vacancies below their long-run equilibrium levels-should result in vacancy rates which similarly fall below their equilibrium or "natural" levels and in so doing put upward pressure on rents. The upward movement in rents should work both to depress demand from existing renters as well as to prompt additions to the rental housing stock; both of these adjustments should in turn enable observed vacancy rates to move in the direction of equilibrium levels. The opposite should similarly hold true, in that factors that move the observed incidence or duration of vacancy to levels in excess of their equilibrium rates should result in downward pressure on rents, diminished pace of new construction, and increased demand from existing renters. In other words, the rate of change in metropolitan rents is determined in part by the deviation in observed vacancy rates from their long-run natural or equilibrium level. 
As suggested above, the deviation from long-run equilibrium values in observed vacancy rates can be decomposed into associated deviations in observed incidence and duration of vacancy from their respective equilibrium values. For example, unexpected fluctuations in the local business cycle may result in some deviation in the local incidence and duration of rental vacancies from long-run equilibrium levels. The factors which importantly affect longrun equilibrium levels of vacancy incidence in local markets include rates of population mobility and population growth, metropolitan population age structure and poverty status, presence of public housing, and the like. Alternatively, factors that affect the cost or returns to rental apartment search and hence the chance of achieving a good match between potential renters and available units, such as indices of the heterogeneity of the metropolitan area rental stock, figure importantly in equilibrium levels of rental vacancy duration.

The above suggests that a model of incidence (or duration) should incorporate those factors that affect the equilibrium level of incidence (or duration) as well as those that cause deviation from the natural level (for example, events related to business cycles). Specifically, the equilibrium level of incidence in the $\mathrm{i}^{\text {th }}$ metropolitan area, $\mathrm{I}_{\mathrm{i}}{ }^{\mathrm{n}}$, is modeled to be:

$\mathrm{I}_{\mathrm{i}}^{\mathrm{n}}=\sum \gamma_{\mathrm{k}} \mathrm{Z}_{\mathrm{ki}}{ }^{\mathrm{I}}+\mathrm{u}_{\mathrm{i}}$

where $Z_{i}^{I}$ is a vector of variables that determines $I_{i}^{n}$. Incidence in the $i^{\text {th }}$ metropolitan area, $I_{i}$, is posited to be:

$\mathrm{I}_{\mathrm{i}}=\mathrm{b}_{0}+\mathrm{b}_{1} \mathrm{I}_{\mathrm{i}}^{\mathrm{n}}+\sum \mathrm{b}_{\mathrm{j}} \mathrm{X}_{\mathrm{ji}}+\mathrm{e}_{\mathrm{i}}$

or

$\mathrm{I}_{\mathrm{i}}=\mathrm{b}_{0}+\sum \omega_{\mathrm{k}} \mathrm{Z}_{\mathrm{ki}}{ }^{\mathrm{I}}+\sum \mathrm{b}_{\mathrm{j}} \mathrm{X}_{\mathrm{ji}}+\mathrm{v}_{\mathrm{i}}$

where $X_{i}$ represents the vector of city-specific shift factors which cause $I_{i}$ to deviate from its long-run equilibrium level, the parameter vector $\omega=b_{1} \gamma$, and $v_{i}=e_{i}+u_{i}\left(e_{i}\right.$ and $u_{i}$ are assumed to be independent). This formulation distinguishes among determinants of the 
equilibrium level of incidence (e.g., population mobility) and factors that cause deviations in observed incidence from the equilibrium level.

In a similar manner, the determinants of intercity variation in observed duration of vacancy can be specified as:

$D_{i}=a_{0}+a_{1} D_{i}^{n}+\sum a_{j} X_{j i}+\phi_{i}$

or

$\mathrm{D}_{\mathrm{i}}=\mathrm{a}_{0}+\sum \psi_{\mathrm{k}} \mathrm{Z}_{\mathrm{ki}}^{\mathrm{D}}+\sum \mathrm{a}_{\mathrm{j}} \mathrm{X}_{\mathrm{ji}}+\tau_{\mathrm{i}}$

where $D_{i}^{n}=\sum \delta_{w} Z_{w i}{ }^{D}+v_{i}, X_{i}$ represents the vector of city-specific shift factors which cause $D_{i}$ to deviate from its long-run equilibrium level, the parameter vector $\psi=\mathrm{a}_{1} \delta$, and $\tau_{\mathrm{i}}=\phi_{\mathrm{i}}+\mathrm{v}_{\mathrm{i}}\left(\phi_{\mathrm{i}}\right.$ and $v_{i}$ are assumed to be independent). In the empirical work that follows, $X_{i}$ is comprised of proxies for unexpected fluctuations in the local economic cycle as well as local area and time specific fixed effects. Equations (9) and (11) are estimated in turn.

In addition to identifying the determinants of incidence and duration, the decomposition of the vacancy rate into its two components creates the opportunity to more fully explore the rental-price adjustment mechanism in local markets. The empirical literature has generally built upon Rosen and Smith's [1983] approach of modeling rent change based on the deviation of the vacancy rate from its natural level. Conceptually, the model views the natural vacancy rate as that rate at which real rent increases equal zero. At that equilibrium level of vacancy, there exists neither an excess demand for nor an excess 
supply of rental housing. ${ }^{14}$ Typically, the rate of change in real rents in city $\mathrm{i}$ is written as a function of deviations in the observed vacancy rate from its equilibrium level:

$\dot{R}_{t}=g\left(V^{n}-V_{t}\right)$

where $\dot{R}_{t}$ is $\mathrm{dR} / \mathrm{dt}$ and, in this paper, $\mathrm{V}^{\mathrm{n}}$ and $\mathrm{V}_{\mathrm{t}}$ are in logs. When $\mathrm{V}_{\mathrm{t}}$ equals $\mathrm{V}^{\mathrm{n}}$, real rents are constant over time. Recall, however, that the observed vacancy rate at time t may be expressed as the product of the incidence of vacancy and duration of vacancy components. In an analogous manner, the equilibrium level of vacancies may be expressed as the product of the equilibrium levels of vacancy incidence and duration, or, in logarithms as:

$V_{t}=I_{t}+D_{t}$

Using those definitions and substituting into the above, the standard formulation of the price adjustment mechanism reduces to a special case of the more general expression:

$$
\begin{aligned}
\dot{R}_{t} & =h\left(I_{t}^{n}-I_{t}\right)+k\left(D_{t}^{n}-D_{t}\right) \\
& =k\left(V^{n}-V_{t}\right)+(h-k)\left(I^{n}-I_{t}\right)
\end{aligned}
$$

where $\mathrm{I}^{\mathrm{n}}$ and $\mathrm{D}^{\mathrm{n}}$ represent the equilibrium levels of vacancy incidence and vacancy duration, respectively. In this more general model, the rate of increase in real rents reflects deviations in observed vacancy incidence and duration from their equilibrium levels; only in the special case when $\mathrm{h}=\mathrm{k}$ does this more general expression reduce to the simpler formulation prevalent in the literature.

\footnotetext{
${ }^{14}$ At the equilibrium level of vacancies, the addition of apartments into the vacancy pool is offset by a proportional flow of units into rental status. Vacancies may be observed even when the rental market is in long-run equilibrium, due to the existence of imperfect information and multiperiod lease contracts. Those features of the rental market may result in a landlord profit maximization that requires that some rental units temporarily remain vacant (see Smith [1987]). Excess supply denotes the amount of vacancies in excess of the equilibrium level, whereas excess demand refers to the reduction in vacancies below the equilibrium level. Assuming a constancy in the equilibrium level of vacancies in a particular metropolitan area in the short-run, deviations in the observed vacancy rate from the equilibrium level reflect either excess supply of or demand for rental housing.
} 
Assuming that the equilibrium levels of vacancy incidence and vacancy duration remain constant over the estimation period for any given city but vary across cities, a pooled crosssection and time-series model may be written as (see Gabriel and Nothaft [1988]):

$\Delta R_{i t}=\beta_{o}+\sum_{j=1}^{N-1} \beta_{j} C_{j}-k V_{i t}-(h-k) I_{i t}+e_{i t}$

where $\Delta R_{i t}=R_{i t}-R_{i, t-1}$. If the empirical estimation reveals that the coefficient of incidence is not significantly different from zero, then the simpler model without that control is preferred.

Wheaton and Torto [1994] have proposed an alternative paradigm that models the equilibrium level of rent and specifies a partial adjustment model to describe the evolution of rent over time. Their model is:

$$
\begin{aligned}
& R_{t}^{*}=V^{n}+\gamma_{A} A_{t}+\gamma_{v} V_{t} \\
& R_{t}-R_{t-1}=\mu\left(R_{t}^{*}-R_{t-1}\right)
\end{aligned}
$$

where $\mathrm{R}^{*}$ is the equilibrium rent, $\mathrm{A}_{\mathrm{t}}$ is a measure of tenant flow (or apartment absorption), and $\mu$ is the speed of adjustment of rent to its equilibrium level. If rent setting is based in part on lease-up time for the rental unit, then a measure of tenant flow should contribute to the determination of equilibrium rents. Again, a more general framework recognizes the decomposition of vacancy into incidence and duration, and the above may be rewritten as:

$$
\begin{aligned}
R_{t}^{*} & =V^{n}+\gamma_{A} A_{t}+\gamma_{I} I_{t}+\gamma_{D} D_{t} \\
& =V^{n}+\gamma_{A} A_{t}+\gamma_{D} V_{t}+\left(\gamma_{I}-\gamma_{D}\right) I_{t} \\
R_{t} & -R_{t-1}=\mu V^{n}+\mu \gamma_{D} V_{t}+\mu\left(\gamma_{I}-\gamma_{D}\right) I_{t}+\mu \gamma_{A} A_{t}-\mu R_{t-1}
\end{aligned}
$$

The above model describes the rental-price adjustment process in each city; pooling across cities, the above expression becomes:

$$
\Delta R_{i t}=\alpha_{o}+\sum_{j=1}^{n-1} \alpha_{j} C_{j}+\mu \gamma_{D} V_{i t}+\mu\left(\gamma_{I}-\gamma_{D}\right) I_{i t}+\mu \gamma_{A} A_{i t}-\mu R_{i, t-1}+v_{i t}
$$


where the $C_{j}$ are city dummies, as in (15). In the empirical work that follows, (15) and (20) are estimated in turn, each with and without the incidence term, and (20) with and without the measure of absorption.

\section{Model Estimation}

\section{Models of Vacancy Duration and Incidence}

As suggested in tables 3 and 4, our computations indicate significant cross-city and intertemporal variation in both the incidence and duration components of rental vacancies. In this section, we undertake the first econometric analyses of those series. Controls for renter population and rental housing stock characteristics were obtained from the metropolitan area files of the American Housing Survey. Variable definitions are contained in Appendix D.

As discussed above, the observed duration of rental vacancies is affected by the determinants of equilibrium levels of vacancy duration, together with proxies for economic and other factors which might cause observed duration of vacancy to deviate from equilibrium levels. Equilibrium levels of vacancy duration reflect local rental market conditions. To the extent apartments are identical, potential tenants minimize search costs (and hence duration of vacancy) by taking the first available unit. As such, we anticipate that observed duration of vacancy will be greater in those metropolitan areas characterized by greater diversity in the types of rental units available. In this research, we employ various measures of the heterogeneity of the metropolitan rental housing stock, including indices of the age, size distribution, physical characteristics, and intrametropolitan location of the stock. In general, we hypothesize that search costs and the observed duration of vacancy vary directly with each measure of heterogeneity of the rental stock.

The effects of rent levels on the equilibrium duration of vacancy are unclear, a priori, because of the potentially conflicting responses of the landlord and the prospective tenant. If 
households seek to minimize shelter costs per unit of housing quality, then higher metropolitan area rent levels suggest higher potential gains from continued housing search. From the perspective of households searching for a rental unit, high rents imply longer rental unit vacancy durations. Landlords, on the other hand, seek to maximize net rental income. The opportunity costs of vacant units rise with the prevailing level of rents. From the landlord perspective, one would expect some damping in duration of vacancy in high rent areas. ${ }^{15}$ Rent levels are represented by tenants' median housing costs for each metropolitan area as computed in the American Housing Survey.

The equilibrium duration of vacancy also may vary with the racial heterogeneity of the metropolitan area population. On the one hand, segmentation and stratification of urban housing markets by race may reduce renter search costs by limiting the search grid, thereby leading to a reduced duration of vacancy. Alternatively, the duration of rental vacancy may be higher in markets characterized by significant individual-level racial bias (whereby raciallyprejudiced landlords turn away well-qualified minority rental applicants and in so doing lengthen the duration of rental vacancies). In the analysis below, we evaluate the effects of population racial distribution on the equilibrium duration of vacancy.

The equilibrium number of annual spells—or incidence—of rental market vacancies largely should reflect the mobility characteristics of the renter population, together with measures of change in the size of renter populations and the availability of below-market rental units. The equilibrium incidence of vacancy will vary directly with measures of population mobility. In the analysis below, population mobility is proxied directly by the percentage of population that moved in the prior year. Additional regressors include the percentage of elderly

\footnotetext{
${ }^{15}$ While this will generally be the case in expensive markets, nonetheless, as discussed in Read [1988] and Arnott [1989], a landlord's decision to set a lower rent will result in a faster rate of unit inspections and hence in a lower duration of vacancy.
} 
and poverty level households. Overall, mobility should be lower among lower-income households. However, mobility rates may be elevated among some elderly households, due to climatic, family, or health-related concerns.

It is hypothesized that the equilibrium incidence of vacancy will be damped in metropolitan areas with greater proportions of rent-controlled or public housing units. Those units typically are available at below-market rents that provide a disincentive for those occupying the units to move.

Population growth as derived from indigenous sources and from interregional migration should affect the equilibrium incidence of rental housing vacancy. While unanticipated population increases lead to lower short-run vacancy rates, areas characterized by a higher rate of expected population growth may have a higher equilibrium incidence of rental vacancies stemming from higher rates of new construction. A priori, it is unclear which of these conflicting influences dominate. We enter the annual rate of population growth into the incidence regression to control for this effect.

Having well-proxied the determinants of equilibrium duration and incidence, we enter additional controls to account for deviations in nominal duration and incidence from equilibrium levels. Those latter controls include MSA- and time-specific fixed effects as well as an indicator of generalized local economic and real estate market weakness. In general, we expect that both the incidence and the duration of vacancy should rise above equilibrium levels during periods of damped demand for rental units. In the analyses reported on below, MSAspecific economic cycles are proxied by a categorical variable indicating the occurrence and timing of a local economic downturn. We further account for intertemporal variation in the incidence and duration of vacancy by way of annual fixed effects. 
Results of the OLS estimation of the duration and incidence of vacancy equations [(9) and (11)] are contained in tables 5 and 6, respectively. As anticipated, the nominal duration and incidence series vary systematically with the vector of proxies for equilibrium levels of those series. In that regard, duration is significantly boosted by measures of the diversity of the rental housing stock, including the proportion of rental units that are new or the proportion of units that are in buildings with seven or more stories. Regression results further indicate a significant reduction in duration of vacancy in areas of higher median housing costs, consistent with the notion that landlord opportunity costs of holding units in vacant status increase with levels of apartment rents. Results of the analysis indicate significantly lower durations of vacancy in areas characterized by higher proportions of minority households. Stratification of metropolitan housing markets by race may limit the search areas and hence the average durations of vacancies for both minority and non-minority renters.

Having controlled for the above set of equilibrium duration determinants, the annual fixed effects coefficients reveal a significantly elevated duration of vacancy during 1990-1992 and 1994. Those results are consistent with the hypothesis that the observed duration of vacancy should rise during a period of generalized economic and rental housing market weakness. Given controls for annual variation in the duration of vacancy measure, results of the analysis indicate little additional explanatory power associated with the local recession indicator. Finally, results also indicate statistically elevated average durations of rental unit vacancies in such metropolitan areas as Houston, Atlanta, New Orleans, Anaheim, San Francisco, Indianapolis, Norfolk, and Birmingham. In contrast, the average duration of vacancy appears to have been significantly depressed during study years in such metropolitan areas as New York, Northern New Jersey, Minneapolis, Seattle, and Portland. 
As shown in table 6 , the incidence of vacancy similarly varies systematically with the vector of proxies for equilibrium incidence. In that regard, the average incidence series varies directly with the percentage elderly population. As suggested above, a variety of concerns, including climatic conditions, family location, and changes in elderly health status may motivate the move decisions of that group. As anticipated, the percentage of renteroccupied units owned by a public housing authority serves to significantly damp the incidence of rental vacancy, as the availability of below-market rents in public housing units works to limit their turnover. However, other indicators of the presence of typically belowmarket rental units, such as the percentage of rental units that are rent-controlled, failed to exert a significant influence on the incidence of vacancy. ${ }^{16}$ Results further indicate that the annual rate of population growth exerts a sizable and significant negative influence on the incidence of rental vacancies. These findings suggest that much of the population growth was unanticipated, and as such resulted in a tightening in rental housing market conditions and a reduction in vacancy incidence.

Having controlled for the above proxies for equilibrium incidence, we do find evidence of a significant decline in vacancy incidence in 1992. We interpret this result as consistent with the tightening in rental market conditions that occurred in that year in the wake of some rebound in macroeconomic activity. As is well appreciated, the strengthening in demand for rental units in 1992 occurred in a market that had seen significantly damped rates of new production over preceding recession years. Having controlled for the annual evolution in the incidence of vacancy, the local recession indicator exerts a negative but not highly significant effect on the incidence of vacancy. Finally, all things equal, a number of

\footnotetext{
${ }^{16}$ The insignificant estimate may reflect that rent controlled units comprised only about 2 percent of rental units in the MSA sample. The states of California, Connecticut, New Jersey, New York, and Massachusetts, and the District of Columbia, are the only areas that have MSAs with rent control.
} 
metropolitan areas were characterized by significantly elevated levels of vacancy incidence over the period of analysis. Those MSAs included St. Louis, Kansas City, Washington D.C., Dallas, Baltimore, Houston, Atlanta, New Orleans, Anaheim, Seattle, Denver, Hartford, Indianapolis, Norfolk, and Birmingham. As is evident in the tables, many MSAs characterized by a significantly elevated incidence of vacancy similarly had significantly higher duration levels.

\section{Models of Residential Rents}

The residential rent models [equations (15) and (20)] are estimated for a pooled crosssection and time-series sample of twenty-nine U.S. metropolitan areas for the years 1987-1996 (table 7). In the estimation of those equations, MSA-level fixed effects were utilized for all but New York, which is reflected in the constant term. Metropolitan area vacancy rates were computed by the authors based on data obtained from the CPI housing sample; as shown above, computed vacancy rates largely coincide with measures published by the Bureau of the Census. ${ }^{17}$ The rental variable R was proxied by the residential rent component of the CPI for each metropolitan area deflated by that area's All Items Excluding Shelter component of the CPI. ${ }^{18}$ As is evident from an inspection of table 7 , certain model specifications test the appropriateness of inclusion of the vacancy incidence series. Further, the empirical analysis

\footnotetext{
${ }^{17}$ In contrast, many early studies (see, for example, Smith [1974], Eubank and Sirmans [1979], Rosen and Smith [1983]), relied on landlord income data supplied by the Institute of Real Estate Management to calculate metropolitan area vacancy rates. Those vacancy rates were not derived on the basis of accepted sampling and statistical procedures. Gabriel and Nothaft [1988] used appropriately-derived Bureau of the Census computations to study vacancy rates at the metropolitan area level.

18 The deflation of the residential rent series conforms to that of Gabriel and Nothaft [1988]. Some earlier studies, notably including Rosen and Smith [1983], estimated the rental price adjustment equation in nominal terms. Deflation of the rental price term is appropriate given the substantial variation in inflation over the 1987-1996 period. CPI rent data were unavailable for the Tampa-St. Petersburg-Clearwater and New Orleans MSAs in 1986, thus only nine years of rent growth are available for these MSAs.
} 
introduces proxies for lagged rents and absorption of rental housing space, as suggested by the Wheaton and Torto [1994] framework.

Results of the estimation of equation (20) show that high vacancy rates significantly impede the rate of increase in residential rents. The estimated coefficients are of appropriate sign across model specifications and significant at the 1 percent level. ${ }^{19}$ Further, those findings in general are consistent with those of prior studies (see, for example, Smith [1979], Rosen and Smith [1983], and Gabriel and Nothaft [1988]) in suggesting the importance of rental vacancy rates to the price adjustment mechanism for rental housing. ${ }^{20}$ As is evident in table 7 , research findings lend credence to the theoretical disaggregation of the vacancy measure into its incidence of vacancy and duration of vacancy components. In general, the coefficient estimates of vacancy incidence are of appropriate sign and statistically significant. Specifically, results of the analysis allow us to reject the restricted formulation prevalent in the literature in favor of a more general specification in which the rate of change in real rents reflects deviations in observed vacancy incidence and duration from their equilibrium levels. ${ }^{21}$ These findings provide new insights regarding the importance of vacancy incidence and duration in the analysis

\footnotetext{
${ }^{19}$ The model in Table 7 specifies that the current-year vacancy rate affects real rent growth over the following year; similar but weaker results were obtained when the current-year vacancy rate was used to explain real rent growth over the past year. The lag relationship in Table 7 is appropriate to the analysis, given that rental lease contracts create a response lag between vacancy rates and rent inflation.

${ }^{20}$ Gabriel and Nothaft [1988] developed and tested an index of rental apartment operating costs. That index was calculated on the basis of data contained in the CPI for the individual metropolitan areas and included estimates of household expenses pertaining to fuel and other utilities, property taxes, and overall price inflation. A change in real operating costs variable was then entered into equation (14), taken to reflect certain cost-push elements associated with real rent changes. The estimated coefficient was both small in magnitude and statistically insignificant and hence was not entered into the current analyses.

${ }^{21}$ Note that the simple t-test of the estimated incidence coefficient in equation (20) is equivalent to a test of the null hypothesis that $\mathrm{h}=\mathrm{k}$ as discussed in equation (14).
} 
of the rent adjustment mechanism for rental housing.

Given an accounting for vacancy incidence and duration, model specifications in table 7 further seek to distinguish between the rental housing adjustment mechanism common to the literature [equations (1) and (2) of table 7] and the partial adjustment framework advocated by Wheaton and Torto [1994] (equations (3) - (7) of table 7). As discussed above, the latter approach suggests the inclusion of lagged residential rent and absorption terms in the rent adjustment equation. Estimation findings indicate that the lagged rent terms are highly significant throughout; however, the absorption terms uniformly fail to achieve an acceptable level of statistical significance. ${ }^{22}$ The lack of significance of the rental space absorption terms pertains both to gross and net measures of that variable. ${ }^{23}$ Note, however, that the partial adjustment specification adds appreciably to the explanatory power of the rental housing price adjustment model; further, as is evident in table 7 , the estimated coefficients on the vacancy rate and incidence variables are largely robust to the inclusion of lagged rent and absorption terms.

Finally, several of the MSA-specific fixed effects coefficients are significant, reflecting the differences between New York and the other cities in the sample. For example, the estimates suggest that renters in Atlanta, Buffalo, Chicago, and Philadelphia experienced higher rates of rent increases - all things equal - than renters in other metropolitan areas. Results for Minneapolis suggest a damped rental price adjustment mechanism relative to other cities in the sample.

\footnotetext{
${ }^{22}$ Recall that absorption rates serve to proxy in part the effects of tenant flows in the determination of residential rents; to some degree, those same effects may be reflected in the incidence term.

Accordingly, in those cases where both incidence and absorption terms are entered in the equations [specifications (5) and (6)], those coefficients may be estimated imprecisely.
} 


\section{Equilibrium Vacancy Rates}

Table 8 contains new estimates of the equilibrium rental vacancy rate for rental housing. As indicated earlier, the natural vacancy rate is defined as that rate for which real rents are constant. In our pooled cross-section and time-series analysis, the equilibrium vacancy rate (from equation (20)) for the $i^{\text {th }}$ city equals $\left(\hat{\alpha}_{0}+\hat{\alpha_{i}}\right) / \hat{\mu}$ where $\hat{\alpha_{i}}$ captures city-specific factors that cause deviation in the natural vacancy rate across metropolitan areas (for New York City, the natural vacancy rate is simply $\left.\hat{\alpha}_{0} / \hat{\mu}\right) .{ }^{24}$ Note here that $\hat{\alpha}_{0}$ represents the estimated constant term and $\hat{\mu}$ is the estimated coefficient on the lagged rent term. Estimates presented in table 8 derive from two specifications, one which holds rent adjustment speed constant across areas as in equation (7) of table 7, the other allowing variation in the lagged rent term across metropolitan areas. As is evident from the table, a restriction across areas in the speed of rent adjustments serves to appreciably reduce variations in those areas in the estimated equilibrium vacancy rate.

The calculations indicate an equilibrium vacancy rate in the 4 to 4.5 percent range. While this is somewhat below other estimates in the literature, direct comparisons should be undertaken with caution. Note first that this paper utilizes a new source of information on rental vacancies computed from a notably reliable survey. Second, the estimates are derived from a larger number of metropolitan areas spanning a longer time frame. ${ }^{25}$ Further, previous estimates have relied on a simpler model that did not account for incidence nor the evolution of

\footnotetext{
${ }^{23}$ While the ideal measure of tenant flows is the rate of gross rental housing space absorption, Wheaton and Torto [1994) had access only to a net absorption measure in analysis of office markets.

${ }^{24}$ Setting equation (20) equal to zero, and recognizing that this implies (from (17)) that $R_{t}^{*}=R_{t-1}$, and substituting from (18) back into (20) yields the formula in the text for the equilibrium vacancy rate.
} 
rent (e.g., model (1) versus (7) in table 7). Finally, this sample includes single-family (58 percent of sample), manufactured housing (3 percent) and multifamily rental units (39 percent); vacancy rates on single-family properties are much lower than on multifamily properties.

\section{Conclusion}

This paper provides derivation and analytical modeling of the duration and incidence of vacancy measures as well as empirical assessment of the importance of those factors to the price adjustment mechanism for rental housing. The study applies new data from the BLS to compute the incidence and duration of vacancy series for major metropolitan areas in the United States and indicates the extent to which variation in residential vacancy rates across areas and over the 1987-1996 period is due to differences in vacancy incidence, vacancy duration, or both. The research then undertakes econometric evaluation of the incidence and duration measures so as to provide new insights regarding the determinants of those indicators. Finally, the incidence and duration measures also are employed to evaluate the price adjustment mechanism for rental housing. In so doing, we utilize those series to compute new cross-city equilibrium rental vacancy rates.

Results of the analysis indicate substantial variation in the incidence and the duration of rental vacancies across metropolitan areas and over time. Comparison of duration estimates with data contained in the American Housing Survey lend credence to the research approach and demonstrate the apparent undercounting of short spells of vacancy duration associated with more traditional rental vacancy datasets. Research findings indicate that the average duration of vacancy varies directly with measures of potential tenant search costs and in areas of higher median housing costs. Accordingly, mechanisms to enhance the flow of information on available units could go some distance toward lowering search costs and improving the

${ }^{25}$ Rosen and Smith indicate that their estimated equilibrium vacancy rates may be inflated due to 
efficiency of rental market allocations. In contrast, the incidence of vacancy varies positively with some measures of population mobility, the presence of public housing units, and population growth. Vacancy incidence reflects in part frictions in the rental housing market--an anticipated and desired consequence of household moves that serve to enhance the efficiency of housing allocations. Results of the analysis further allow us to reject the restricted empirical formulation of the rental price adjustment mechanism prevalent in the literature in favor of a more general specification in which the rate of change in real rents reflects deviations in observed vacancy incidence and duration from their equilibrium levels. Based on this innovation, the research further provides new estimates of equilibrium vacancy rates for a large set of metropolitan areas over the 1987-1996 period. Overall, findings lend credence to model specification and provide new insights regarding the importance of vacancy incidence and duration in the analysis of the rental housing markets.

computational procedures utilized by the authors in calculation of city-level vacancy rates. 


\section{References}

Arnott, R., "Housing Vacancies, Thin Markets, and Idiosyncratic Tastes," Journal of Real Estate Finance and Economics, 2 (1): 5-30, 1989.

Blank, D. M. and Winnick, L., "The Structure of the Housing Market," Quarterly Journal of Economics, 67 (2): 181-208, 1953.

Belsky, E., "Rental Vacancy Rates: A Policy Primer," Housing Policy Debate, 3 (3): 793-814, 1992.

Belsky, E. and Goodman, J., "Explaining the Vacancy Rate-Rent Paradox of the 1980s," Journal of Real Estate Research, 11 (3): 309-23, 1996.

Eubank, A. A. and Sirmans, C. F., "The Price Adjustment Mechanism for Rental Housing in the United States," Quarterly Journal of Economics, 93 (1): 163-83, 1979.

Gabriel, S. and Nothaft, F., "Rental Housing Markets and the Natural Vacancy Rate," Journal of the American Real Estate and Urban Economics Association, 16 (4): 419-29, 1988.

Johnson, G. and Layard, P., "The Natural Rate of Unemployment: Explanation and Policy," in Ashenfelter and Layard (eds.) Handbook of Labor Economics, 2, Elsevier Science Publishers, 1986.

Leighton, L. and Mincer, J., "Labor Turnover and Youth Unemployment," in Freeman and Wise (eds) The Youth Labor Market Problem, National Bureau of Economic Research, pp. 235 - 275, 1982.

Muller, R., "Rent Control and Vacancy Rates in Canada," QSEP Research Report No. 275, McMaster University, Canada, 1991.

Read, C., "Price Strategies for Indiosyncratic Goods-The Case of Housing," Journal of the American Real Estate and Urban Economics Association, 16 (4): 379-95.

Rosen, K., and Smith, L., "The Price Adjustment Process and the Natural Vacancy Rate," American Economic Review, 73 (4): 779-86, 1983.

Rydell, P., "Vacancy Duration and Housing Market Condition," unpublished working paper, Rand Housing Assistance and Supply Experiment, RAND/WN-10074-HUD, 1978.

Smith, L., "A Note on the Price Adjustment Mechanism for Rental Housing," American Economic Review, 64 (3): 478-81, 1974.

U.S. Department of Labor, BLS Handbook of Methods, Bulletin 2414, Chapter 19: "The Consumer Price Index," 1992. 
Vandell, K. and Riddiough, T., "The Impact of RTC Dispositions on Local Housing and Real Estate Markets," Housing Policy Debate, 2 (1): 49-92, 1991.

Wheaton, W. and Torto, R., "Office Rent Indices and Their Behavior over Time," Journal of Urban Economics, 35 (2): 121-139, 1994. 
Table 1

Rental Vacancy Rates in Various Metropolitan Areas, 1987-1993

\begin{tabular}{|c|c|c|c|c|c|c|c|c|c|}
\hline Metropolitan Area & 1987 & 1988 & 1989 & 1990 & 1991 & 1992 & 1993 & Mean & $\begin{array}{c}\text { Standard } \\
\text { Deviation }\end{array}$ \\
\hline Atlanta MSA & $\mathrm{L}$ & & & & $\mathrm{H}$ & & & & \\
\hline BLS & 5.3 & 8.9 & 9.7 & 13.6 & 15.6 & 14.5 & 10.6 & 11.2 & 3.4 \\
\hline Census & 6.4 & 9.7 & 12.5 & 11.6 & 12.9 & 11.2 & 9.6 & 10.6 & 2.2 \\
\hline \multicolumn{10}{|l|}{ Baltimore MSA } \\
\hline BLS & 6.9 & 6.9 & 6.8 & 6.8 & 6.0 & 8.5 & 8.0 & 7.1 & 0.8 \\
\hline Census & 8.3 & 5.4 & 4.9 & 5.2 & 7.4 & 7.0 & 8.5 & 6.7 & 1.5 \\
\hline Chicago $^{1}$ & $\mathrm{~L}$ & & & & & $\mathrm{H}$ & & & \\
\hline BLS (CMSA) & 4.6 & 5.8 & 6.1 & 6.5 & 6.4 & 6.6 & 6.6 & 6.1 & 0.7 \\
\hline Census(PMSA) & 6.1 & 6.8 & 6.4 & 6.6 & 7.3 & 8.4 & 7.3 & 7.0 & 0.8 \\
\hline Los Angeles- & & & & & & & $\mathrm{H}$ & & \\
\hline Long Beach MSA & $\mathrm{L}$ & & & & & & & & \\
\hline BLS & 3.8 & 5.6 & 5.2 & 5.9 & 6.2 & 6.7 & 8.5 & 6.0 & 1.3 \\
\hline Census & 4.4 & 5.5 & 5.8 & 6.2 & 6.7 & 8.2 & 9.5 & 6.6 & 1.7 \\
\hline \multicolumn{10}{|l|}{$\begin{array}{l}\text { Minneapolis- } \\
\text { St.Paul MSA }\end{array}$} \\
\hline BLS & 3.1 & 4.6 & 5.5 & 4.7 & 4.0 & 5.9 & 3.2 & 4.4 & 1.0 \\
\hline Census & 5.3 & 6.5 & 6.3 & 6.5 & 6.7 & 5.5 & 5.2 & 6.0 & 0.6 \\
\hline Nashville MSA & & & & $\mathrm{H}$ & & & & & \\
\hline BLS & 6.1 & 7.0 & 9.2 & 9.2 & 8.6 & 9.0 & 6.2 & 7.9 & 1.3 \\
\hline Census & 8.0 & 8.4 & 11.2 & 11.3 & 8.8 & 4.3 & 4.9 & 8.1 & 2.7 \\
\hline New York ${ }^{2}$ & $\mathrm{~L}$ & & & & & $\mathrm{H}$ & & & \\
\hline BLS (city) & 1.4 & 2.9 & 2.5 & 2.8 & 3.9 & 4.2 & 3.9 & 3.1 & 0.9 \\
\hline Census(PMSA) & 2.4 & 2.8 & 3.3 & 4.7 & 5.1 & 5.5 & 5.0 & 4.1 & 1.2 \\
\hline San Diego MSA & $\mathrm{L}$ & & & & & $\mathrm{H}$ & & & \\
\hline BLS & 4.1 & 5.4 & 5.9 & 5.2 & 6.3 & 8.5 & 7.3 & 6.1 & 1.3 \\
\hline Census & 6.2 & 8.5 & 6.6 & 6.9 & 6.3 & 8.3 & 7.8 & 7.2 & 1.0 \\
\hline \multicolumn{10}{|l|}{$\begin{array}{l}\text { Tampa-St.Peters- } \\
\text { burg-Clearwater }\end{array}$} \\
\hline BLS & 5.7 & 9.0 & 11.6 & 11.5 & 15.2 & 13.2 & 14.1 & 11.5 & 3.0 \\
\hline Census & 11.3 & 13.3 & 11.3 & 10.4 & 10.6 & 8.8 & 9.0 & 10.7 & 1.5 \\
\hline \multicolumn{10}{|l|}{$\begin{array}{l}\text { Washington DC- } \\
\text { MD-VA MSA }\end{array}$} \\
\hline BLS & 2.2 & 4.2 & 4.6 & 6.7 & 7.1 & 6.3 & 5.5 & 5.2 & 1.6 \\
\hline Census & 4.8 & 4.6 & 5.8 & 6.7 & 7.9 & 8.8 & 8.4 & 6.7 & 1.7 \\
\hline
\end{tabular}

\footnotetext{
${ }^{1}$ The Chicago CMSA includes the Chicago PMSA, Aurora-Elgin PMSA, Gary-Hammond PMSA, Joliet PMSA, Kenosha PMSA, and Lake County PMSA.

${ }^{2}$ The New York PMSA includes New York City and Westchester, Rockland, and Putnam Counties.
} 
Table 2

Effect of Interval Length on Incidence and Duration Estimates

\begin{tabular}{|c|c|c|c|c|c|}
\hline \multirow[b]{2}{*}{$\begin{array}{l}\text { Interval Length } \\
\text { and Time Period }\end{array}$} & \multirow[b]{2}{*}{$\begin{array}{l}\text { Vacancy } \\
\text { Rate }\end{array}$} & \multirow[b]{2}{*}{$\begin{array}{l}\text { Vacancy } \\
\text { Incidence }\end{array}$} & \multicolumn{2}{|c|}{ Duration } & \multirow{2}{*}{$\begin{array}{c}\text { Proportion } \\
\text { Continuously } \\
\text { Occupied }\end{array}$} \\
\hline & & & $\begin{array}{c}\text { Fraction } \\
\text { of } \\
\text { Period }\end{array}$ & Months & \\
\hline
\end{tabular}

\section{Six-month interval}

$\begin{array}{rccccc}\text { First period } & .063 & .302 & .208 & 1.45 & .698 \\ \text { Second period } & .076 & .296 & .256 & 1.79 & .704 \\ \text { Third period } & .078 & .310 & .252 & 1.77 & .690 \\ \text { Fourth period } & .080 & .293 & .272 & 1.90 & .707\end{array}$

Twelve-month interval

.128

1.67

.567

Third and fourth

.079

.523

.150

1.95

.564

24-month interval

First through fourth

.072

.970

.074

1.86

.402

Note: Analysis uses housing units continuously observed in rental market for first five survey dates; time frame is January 1987 through June 1989 and sample size is 23,895 rental units. 
Table 3

Decomposition of Vacancy Rate into Incidence and Duration

\begin{tabular}{|c|c|c|c|c|c|c|c|}
\hline \multirow{2}{*}{ Metropolitan Area } & \multirow[b]{2}{*}{$\begin{array}{l}\text { Time } \\
\text { Period } \\
\end{array}$} & \multirow[b]{2}{*}{$\begin{array}{c}\text { Vacancy } \\
\text { Rate }\end{array}$} & \multirow[b]{2}{*}{ Incidence } & \multicolumn{2}{|c|}{ Duration } & \multirow{2}{*}{$\begin{array}{l}\text { Proportion } \\
\text { Continuously } \\
\text { Occupied }\end{array}$} & \multirow[b]{2}{*}{$\begin{array}{c}\text { Sample } \\
\text { Size }\end{array}$} \\
\hline & & & & $\begin{array}{l}\text { Percent of } \\
\text { Period }\end{array}$ & Months & & \\
\hline \multirow{6}{*}{ Los Angeles-Long Beach City } & $1 / 87-6 / 88$ & 2.3 & 34.1 & 6.6 & 0.9 & 72.3 & 1070 \\
\hline & $1 / 90-6 / 91$ & 2.7 & 41.4 & 6.4 & 0.8 & 68.4 & 1245 \\
\hline & $1 / 93-6 / 94$ & 3.6 & 30.9 & 11.7 & 1.5 & 74.5 & 1231 \\
\hline & $1 / 87-6 / 88$ & 4.6 & 44.9 & 10.1 & 1.3 & 64.1 & 1146 \\
\hline & $1 / 90-6 / 91$ & 5.7 & 48.8 & 11.7 & 1.5 & 59.5 & 1336 \\
\hline & $1 / 93-6 / 94$ & 9.9 & 57.1 & 17.4 & 2.3 & 53.0 & 1490 \\
\hline \multirow[t]{3}{*}{ Chicago, IL-IN-WI } & $1 / 87-6 / 88$ & 5.9 & 41.4 & 14.1 & 1.8 & 64.6 & 1284 \\
\hline & $1 / 90-6 / 91$ & 7.1 & 43.1 & 16.6 & 2.2 & 61.4 & 1191 \\
\hline & $1 / 93-6 / 94$ & 7.1 & 40.0 & 17.7 & 2.3 & 64.4 & 1208 \\
\hline \multirow{3}{*}{ Washington, DC-MD-VA } & $1 / 87-6 / 88$ & 3.2 & 42.3 & 7.5 & 1.0 & 64.6 & 531 \\
\hline & $1 / 90-6 / 91$ & 7.8 & 51.1 & 15.2 & 2.0 & 59.0 & 542 \\
\hline & $1 / 93-6 / 94$ & 6.6 & 49.7 & 13.2 & 1.7 & 59.9 & 528 \\
\hline \multirow[t]{3}{*}{ Houston, TX } & $1 / 87-6 / 88$ & 20.4 & 74.8 & 27.3 & 3.5 & 41.2 & 567 \\
\hline & $1 / 90-6 / 91$ & 16.8 & 64.1 & 26.2 & 3.4 & 44.9 & 629 \\
\hline & $1 / 93-6 / 94$ & 12.0 & 61.9 & 19.4 & 2.5 & 49.0 & 599 \\
\hline
\end{tabular}


Table 4

Duration of Vacancy

\begin{tabular}{|c|c|c|c|}
\hline \multirow{2}{*}{$\begin{array}{c}\text { Metropolitan Area } \\
\text { and Duration of Vacancy }\end{array}$} & \multicolumn{2}{|c|}{ Distribution of Vacant Rental Units } & $\begin{array}{c}\text { Percent of Vacancy Spells } \\
\text { Over Prior Year: }\end{array}$ \\
\hline & $\begin{array}{c}\text { American Housing } \\
\text { Survey }\end{array}$ & BLS & BLS \\
\hline
\end{tabular}

\section{Dallas}

Less than 6 months

79.5

11.8

6-12 months

12-24 months

24 months or more

Vacancy Rate (Sample Size)

\section{Los Angeles}

Less than 6 months

6-12 months

12-24 months

24 months or more

Vacancy Rate (Sample Size)

\section{Philadelphia}

Less than 6 months

6-12 months

12-24 months

24 months or more

Vacancy Rate (Sample Size)

6.2

2.6

20.0

89.3

4.0

4.4

2.2

8.2

62.3

10.3

5.6

22.1

12.1
Vacancy Rate (Sample Size)

Washington, DC

Less than 6 months

6-12 months

12-24 months

24 months or more

Vacancy Rate (Sample Size)
88.0

8.0

2.9

0.9

7.3

55.8

28.1

16.2

0.0

12.3

(350)

74.1

15.1

10.8

0.0

5.1

(914)

74.3

15.3

10.4

0.0

5.8

(617)

90.7

9.3

0.0

0.0

4.0

(663)

83.4

6.5

0.8

9.2

9.3
86.4

10.4

$3.2^{1}$

94.9

3.7

$1.4^{1}$

92.9

5.0

$2.0^{1}$

96.3

2.9

$0.8^{1}$

95.2

3.4

$1.3^{1}$

1. Duration of vacancy is 12 months or more.

Source: American Housing Survey: Current Housing Reports - H170/89-4, H170/89-7, H170/89-18, H170/89-33, and H170/89-39. 
Table 5

Determinants of the Duration of Rental Vacancies

\begin{tabular}{|c|c|c|}
\hline Variable & Coefficient Estimate & t-Statistic \\
\hline Intercept & 2.880 & 6.22 \\
\hline Rental Units Percent & 4.185 & 5.60 \\
\hline 4+ Bedrooms Percent & -7.463 & -1.38 \\
\hline 7+ Stories Percent & 15.682 & 6.19 \\
\hline Median Housing Costs & -0.004 & -4.27 \\
\hline Black or Hispanic Percent & -3.052 & -3.21 \\
\hline Central City Percent & -0.682 & -1.20 \\
\hline \multicolumn{3}{|l|}{ Metropolitan Area Dummy } \\
\hline Anaheim & 1.109 & 3.93 \\
\hline Atlanta & 1.049 & 3.39 \\
\hline Birmingham & 0.844 & 2.46 \\
\hline Houston & 1.176 & 3.36 \\
\hline Indianapolis & 1.869 & 5.53 \\
\hline Minneapolis & -1.318 & -3.78 \\
\hline New Orleans & 2.760 & 7.35 \\
\hline New York & -4.420 & -5.74 \\
\hline Norfolk & 1.060 & 2.68 \\
\hline Northern New Jersey & -0.635 & -2.23 \\
\hline Portland & -0.961 & -3.41 \\
\hline San Francisco & 1.476 & 3.93 \\
\hline Seattle & -1.116 & -3.66 \\
\hline \multicolumn{3}{|l|}{ Year Dummy } \\
\hline 1990 & 0.296 & 1.79 \\
\hline 1991 & 0.856 & 4.83 \\
\hline 1992 & 0.408 & 1.77 \\
\hline 1994 & 0.631 & 2.85 \\
\hline Recession & 0.154 & 0.96 \\
\hline Memo: Goodness-of-fit (Adj. $\mathrm{R}^{2}$ ) & 0.80 & -- \\
\hline
\end{tabular}

Notes: The dependent variable is the duration of vacancy in months. The regression is based on sample of 64 metropolitan area and time-series observations of rental housing vacancy duration. The data span 31 MSAs captured by the metropolitan-area AHS over 1986-94. 
Table 6

Determinants of the Incidence of Rental Vacancies

\begin{tabular}{|c|c|c|}
\hline$\underline{\text { Variable }}$ & $\underline{\text { Coefficient Estimate }}$ & $\underline{\mathrm{t}-\text { Statistic }}$ \\
\hline Intercept & 0.186 & 1.60 \\
\hline Elderly Percent & 1.917 & 5.21 \\
\hline Recent Mover Percent & 0.290 & 0.74 \\
\hline Poverty Percent & 0.174 & 0.84 \\
\hline Rent Controlled Percent & 0.152 & 0.93 \\
\hline Public Housing Percent & -2.010 & -4.17 \\
\hline Population Growth & -1.326 & -2.54 \\
\hline \multicolumn{3}{|l|}{ Metropolitan Area Dummy } \\
\hline Anaheim & 0.120 & 3.08 \\
\hline Atlanta & 0.308 & 6.16 \\
\hline Baltimore & 0.086 & 2.28 \\
\hline Birmingham & 0.307 & 5.54 \\
\hline Cleveland & 0.044 & 1.09 \\
\hline Dallas & 0.252 & 5.01 \\
\hline Denver & 0.258 & 4.91 \\
\hline Hartford & 0.189 & 4.66 \\
\hline Houston & 0.386 & 6.12 \\
\hline Indianapolis & 0.121 & 2.84 \\
\hline Kansas City & 0.219 & 5.07 \\
\hline New Orleans & 0.219 & 4.39 \\
\hline Norfolk & 0.387 & 6.47 \\
\hline Northern New Jersey & 0.044 & 1.03 \\
\hline St. Louis & 0.200 & 5.15 \\
\hline San Diego & 0.075 & 1.80 \\
\hline Seattle & 0.128 & 2.66 \\
\hline Washington & 0.116 & 2.84 \\
\hline \multicolumn{3}{|l|}{ Year Dummy } \\
\hline 1989 & 0.030 & 1.34 \\
\hline 1991 & -0.004 & -0.14 \\
\hline 1992 & -0.090 & -2.61 \\
\hline Recession & -0.042 & -1.85 \\
\hline Memo: Goodness-of-fit (Adj. $R^{2}$ ) & 0.80 & -- \\
\hline
\end{tabular}

Notes: The dependent variable is the annual rate of incidence of vacancy. The regression is based on sample of 64 metropolitan area and time-series observations of vacancy incidence. The data span 31 MSAs captured by the metropolitan-area AHS over 1986-94. 
Table 7

Determinants of Percentage Change in Real Residential Rent

Coefficient Estimate (absolute value of t-statistic in parenthesis)

\begin{tabular}{|c|c|c|c|c|c|c|c|}
\hline Variable & (1) & (2) & (3) & (4) & (5) & (6) & (7) \\
\hline Intercept & $-.103^{*}$ & $-.117 *$ & $.941 *$ & $.907 *$ & $.932 *$ & $.905^{*}$ & $.946^{*}$ \\
\hline Anchorage & .010 & .016 & $-.074 *$ & $-.071 *$ & $-.068 *$ & $-.066^{*}$ & $-.070 *$ \\
\hline Atlanta & $.034 *$ & $.037 *$ & $.018 *$ & $.018 *$ & $.022 *$ & $.022 *$ & $.021 *$ \\
\hline Baltimore & $.017 * *$ & $.016^{* * *}$ & .009 & .008 & .007 & .007 & .006 \\
\hline Boston & .005 & .004 & .001 & .002 & -.001 & .000 & -.000 \\
\hline Buffalo & .012 & $.015^{* * *}$ & $.016^{*}$ & $.017 *$ & $.020^{*}$ & $.020 *$ & $.019 *$ \\
\hline Chicago & $.023 *$ & $.021 *$ & $.021 *$ & $.022 *$ & $.020 *$ & $.021 *$ & $.020 *$ \\
\hline Cincinnati & $.018 *$ & $.017 * *$ & .009 & .010 & .008 & .008 & .007 \\
\hline Cleveland & $.026 *$ & $.025 *$ & .010 & .012 & .008 & .010 & .008 \\
\hline Dallas & $.017 * *$ & $.023 *$ & $-.031 *$ & $-.029 *$ & $-.025^{*}$ & $-.024 *$ & $-.026^{*}$ \\
\hline Denver & .014 & $.020 *$ & $-.033 *$ & $-.032 *$ & $-.027 *$ & $-.027 *$ & $-.028 *$ \\
\hline Detroit & .008 & .007 & -.005 & -.004 & -.006 & -.005 & -.006 \\
\hline Honolulu & -.005 & -.005 & -.000 & .000 & -.001 & -.000 & -.001 \\
\hline Houston & $.043 *$ & $.048 *$ & -.016 & -.013 & -.012 & -.009 & -.012 \\
\hline Kansas City & $.017 * *$ & $.022 *$ & -.005 & -.004 & -.001 & .000 & -.001 \\
\hline Los Angeles & .008 & .011 & .003 & .003 & .006 & .005 & .005 \\
\hline Miami & $.016^{* *}$ & $.016^{* *}$ & $-.026^{*}$ & $-.024 *$ & $-.026^{*}$ & $-.025^{*}$ & $-.028 *$ \\
\hline Milwaukee & .005 & .004 & .002 & .002 & .002 & .001 & .001 \\
\hline Minneapolis & $-.016^{* *}$ & $-.017 *$ & $-.039 *$ & $-.038 *$ & $-.041 *$ & $-.040 *$ & $-.041 *$ \\
\hline New Orleans & $.026^{*}$ & $.029 *$ & $-.033 *$ & $-.029 *$ & $-.031 *$ & $-.027 *$ & $-.030 *$ \\
\hline Philadelphia & $.027 *$ & $.027 *$ & $.029 *$ & $.029 *$ & $.029 *$ & $.029 *$ & $.028 *$ \\
\hline Pittsburgh & $.017 * *$ & $.017 * *$ & -.004 & -.002 & -.004 & -.002 & -.004 \\
\hline Portland, OR & .012 & .014 & -.001 & -.001 & .001 & .001 & .000 \\
\hline Saint Louis & .009 & .014 & -.012 & -.012 & -.008 & -.008 & -.008 \\
\hline San Diego & -.003 & .000 & -.008 & -.009 & -.004 & -.006 & -.005 \\
\hline San Francisco & .002 & .003 & .011 & .009 & .011 & .010 & .010 \\
\hline Seattle & .012 & $.016^{* *}$ & .004 & .003 & .007 & .006 & .006 \\
\hline Tampa & $.036^{*}$ & $.041 *$ & .002 & .004 & .007 & .008 & .006 \\
\hline Washington & .014 & $.016^{* *}$ & .013 & .012 & .014 & $.014 * *$ & $.014 * *$ \\
\hline Vacancy Rate & $\begin{array}{l}-.031 * \\
(8.32)\end{array}$ & $\begin{array}{l}-.027 * \\
(6.21)\end{array}$ & $\begin{array}{l}-.030^{*} \\
(8.59)\end{array}$ & $\begin{array}{l}-.030^{*} \\
(9.02)\end{array}$ & $\begin{array}{l}-.026^{*} \\
(6.41)\end{array}$ & $\begin{array}{l}-.026^{*} \\
(6.65)\end{array}$ & $\begin{array}{l}-.025^{*} \\
(6.55)\end{array}$ \\
\hline $\begin{array}{l}\text { Vacancy } \\
\text { Incidence }\end{array}$ & -- & $\begin{array}{l}-.019 * * \\
(1.83)\end{array}$ & -- & -- & $\begin{array}{l}-.020^{*} \\
(2.23)\end{array}$ & $\begin{array}{l}-.019 * \\
(2.10)\end{array}$ & $\begin{array}{l}-.021^{*} \\
(2.25)\end{array}$ \\
\hline Rent (t-1) & -- & -- & $\begin{array}{l}-.220^{*} \\
(8.65)\end{array}$ & $\begin{array}{l}-.212^{*} \\
(8.14)\end{array}$ & $\begin{array}{l}-.222 * \\
(8.76)\end{array}$ & $\begin{array}{c}-.215^{*} \\
(8.28)\end{array}$ & $\begin{array}{l}-.224 * \\
(8.95)\end{array}$ \\
\hline $\begin{array}{l}\text { Absorption } \\
\text { (gross) }\end{array}$ & -- & -- & $\begin{array}{c}-.003 \\
(0.67)\end{array}$ & -- & $\begin{array}{r}-.003 \\
(0.63)\end{array}$ & -- & -- \\
\hline $\begin{array}{l}\text { Absorption } \\
\text { (net) }\end{array}$ & -- & -- & -- & $\begin{array}{r}.065 \\
(1.49)\end{array}$ & -- & $\begin{array}{r}.055 \\
(1.25)\end{array}$ & -- \\
\hline $\bar{R}^{2}$ & .233 & .240 & .408 & .412 & .417 & .420 & .419 \\
\hline
\end{tabular}

Note: Models estimated with 288 observations. Asterisk denotes significance at 5\% level; double asterisk denotes significance at $10 \%$ level. Rent measures are from the CPI. Vacancy Rate, Incidence and Absorption are from authors' calculations of data provided by the BLS. 
Table 8

\section{Estimated Natural Vacancy Rates}

\begin{tabular}{|c|c|c|}
\hline Metropolitan Area & $\begin{array}{l}\mathrm{V}^{\mathrm{n}} \text { with Rent Adjustment } \\
\text { Speed Equal across Areas }\end{array}$ & $\begin{array}{c}\mathrm{V}^{\mathrm{n}} \text { with Variable } \\
\text { Rent Adjustment Speed }\end{array}$ \\
\hline Anchorage & 3.9 & 4.2 \\
\hline Atlanta & 4.3 & 3.8 \\
\hline Baltimore & 4.3 & 4.4 \\
\hline Boston & 4.2 & 3.7 \\
\hline Buffalo & 4.3 & 4.5 \\
\hline Chicago & 4.3 & 4.3 \\
\hline Cincinnati & 4.3 & 4.5 \\
\hline Cleveland & 4.3 & 4.5 \\
\hline Dallas & 4.1 & 4.2 \\
\hline Denver & 4.1 & 4.2 \\
\hline Detroit & 4.2 & $--*$ \\
\hline Honolulu & 4.2 & $--*$ \\
\hline Houston & 4.2 & 4.3 \\
\hline Kansas City & 4.2 & 3.4 \\
\hline Los Angeles & 4.3 & 1.4 \\
\hline Miami & 4.1 & 4.4 \\
\hline Milwaukee & 4.2 & $--*$ \\
\hline Minneapolis & 4.0 & 2.1 \\
\hline New Orleans & 4.1 & 4.1 \\
\hline New York & 4.2 & 4.3 \\
\hline Philadelphia & 4.4 & 4.2 \\
\hline Pittsburgh & 4.2 & 4.4 \\
\hline Portland, OR & 4.2 & 2.6 \\
\hline Saint Louis & 4.2 & 4.0 \\
\hline San Diego & 4.2 & --* \\
\hline San Francisco & 4.3 & 4.1 \\
\hline Seattle & 4.3 & 4.1 \\
\hline Tampa & 4.3 & 4.5 \\
\hline Washington & 4.3 & 4.3 \\
\hline
\end{tabular}

Source: $\mathrm{V}^{\mathrm{n}}$ estimates with equal rent adjustment speeds are computed from the parameter estimates in equation (7) of Table 7. $\mathrm{V}^{\mathrm{n}}$ estimates with variable adjustment speeds are computed from a similar model in which the parameter of the lagged rent variable varies by metropolitan area. 
Appendix A

Tabulation of Vacancy Spells During a Six-Month Interval

\begin{tabular}{|c|c|c|c|}
\hline First Observation & \multicolumn{2}{|c|}{ Second Observation } & \multirow{2}{*}{$\begin{array}{r}\text { Number } \\
\text { of Spells } \\
\text { of Vacancy }\end{array}$} \\
\hline $\begin{array}{c}\text { Occupancy } \\
\text { Status }\end{array}$ & $\begin{array}{c}\text { Occupancy } \\
\text { Status }\end{array}$ & $\begin{array}{l}\text { Length of } \\
\text { Occupancy }\end{array}$ & \\
\hline Occupied & Occupied & 6 months or more & 0 \\
\hline Occupied & Occupied & Less than 6 months & 1 \\
\hline Occupied & Vacant & N/A & 1 \\
\hline Vacant & Occupied & N/A & 1 \\
\hline Vacant & Vacant & N/A & 1 \\
\hline
\end{tabular}

Note: N/A is "not applicable" 


\section{Appendix B}

\section{Tabulation of Vacancy Spells During a Twelve-Month Interval}

\begin{tabular}{|c|c|c|c|c|c|}
\hline First Observation & \multicolumn{2}{|c|}{ Second Observation } & \multicolumn{3}{|c|}{ Third Observation } \\
\hline $\begin{array}{c}\text { Occupancy } \\
\text { Status }\end{array}$ & $\begin{array}{c}\text { Occupancy } \\
\text { Status }\end{array}$ & $\begin{array}{l}\text { Length of } \\
\text { Occupancy }\end{array}$ & $\begin{array}{c}\text { Occupancy } \\
\text { Status }\end{array}$ & $\begin{array}{l}\text { Length of } \\
\text { Occupancy }\end{array}$ & $\begin{array}{r}\text { Number } \\
\text { of Spells } \\
\text { of Vacancy }\end{array}$ \\
\hline Occupied & Occupied & $\begin{array}{c}6 \text { months } \\
\text { or more }\end{array}$ & Occupied & $\begin{array}{l}6 \text { months } \\
\text { or more }\end{array}$ & 0 \\
\hline Occupied & Occupied & $\begin{array}{l}6 \text { months } \\
\text { or more }\end{array}$ & Occupied & $\begin{array}{c}\text { Less than } 6 \\
\text { months }\end{array}$ & 1 \\
\hline Occupied & Occupied & $\begin{array}{l}6 \text { months } \\
\text { or more }\end{array}$ & Vacant & N/A & 1 \\
\hline Occupied & Occupied & $\begin{array}{c}\text { Less than } 6 \\
\text { months }\end{array}$ & Occupied & $\begin{array}{l}6 \text { months } \\
\text { or more }\end{array}$ & 1 \\
\hline Occupied & Occupied & $\begin{array}{c}\text { Less than } 6 \\
\text { months }\end{array}$ & Occupied & $\begin{array}{c}\text { Less than } 6 \\
\text { months }\end{array}$ & 2 \\
\hline Occupied & Occupied & $\begin{array}{c}\text { Less than } 6 \\
\text { months }\end{array}$ & Vacant & N/A & 2 \\
\hline Occupied & Vacant & N/A & Occupied & N/A & 1 \\
\hline Occupied & Vacant & N/A & Vacant & N/A & 1 \\
\hline Vacant & Occupied & N/A & Occupied & $\begin{array}{l}6 \text { months } \\
\text { or more }\end{array}$ & 1 \\
\hline Vacant & Occupied & N/A & Occupied & $\begin{array}{c}\text { Less than } 6 \\
\text { months }\end{array}$ & 2 \\
\hline Vacant & Occupied & N/A & Vacant & N/A & 2 \\
\hline Vacant & Vacant & N/A & Occupied & N/A & 1 \\
\hline Vacant & Vacant & N/A & Vacant & N/A & 1 \\
\hline
\end{tabular}

Note: N/A is "not applicable" 


\section{Appendix C}

\section{Effect of Changes in Rental Stock Status on Vacancy and Incidence Rates}

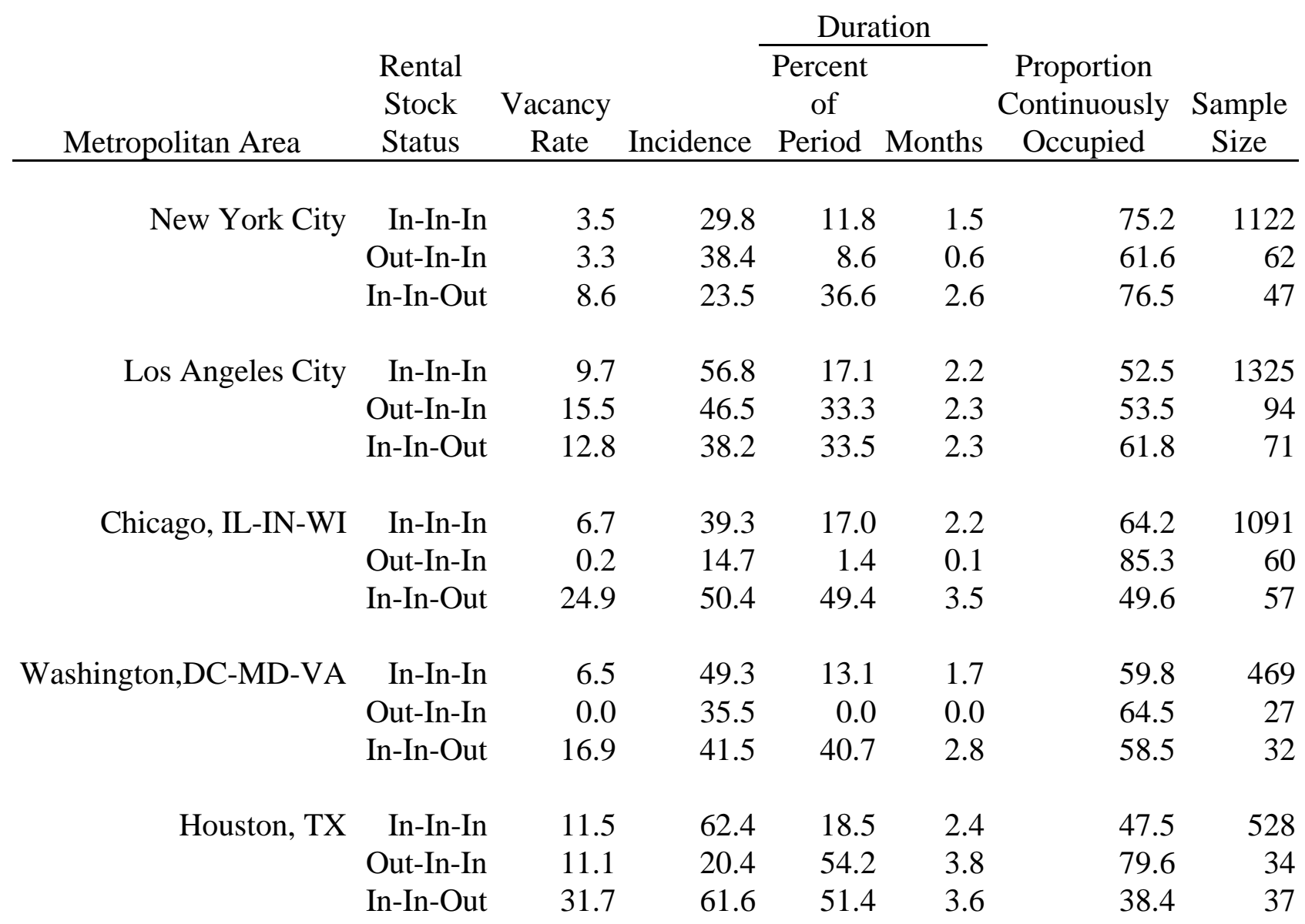

Note: The analytic sample uses rental housing units observed during the $13^{\text {th }}-15^{\text {th }}$ survey dates (time frame is January 1993 through June 1994). For each market, estimates are shown for apartments that are observed to be in the rental stock for three consecutive surveys (labeled "In-In-In") and for apartments that are in the stock for only two consecutive surveys (labeled "Out-In-In" and "In-In-Out" if missing the first or third survey, respectively). Some units are designated as "Out" because of incomplete field reviews. 


\section{Appendix D Variable Definitions}

Duration

New Units Percent

4+ Bedrooms Percent

7+ Stories Percent

Median Housing Costs

Black or Hispanic Percent

Central City Percent

Incidence

Elderly Percent

Recent Mover Percent

Poverty Percent

Rent Controlled Percent

Public Housing Percent

Population Growth

Recession

Vacancy Rate

Rent

Absorption (Gross)

Absorption (Net)
Duration of vacancy in months in rental housing (authors calculation from BLS data)

The percentage of all renter-occupied units that are new (built within the past 15 years)

The percentage of all renter-occupied units with 4 or more bedrooms

The percentage of all renter-occupied units in structures with 7 or more stories

Real median housing costs for all renter-occupied units (1989 dollars)

The percentage of population in rental housing that is Black or Hispanic

The percentage of all current renter-occupied units located within the 1983 or 1994 MSA boundaries that are within the 1983 or 1994 central-city boundaries (for data collected prior to 1994 the 1983 boundaries are used)

Annual rate of incidence of vacancy in rental housing (authors calculation from BLS data)

Percentage of population in housing units that is 65 years of age of older

Percentage of population in housing units that has moved in the past year

Percentage of population in housing units that is below the poverty level

Percentage of all renter-occupied units that are rent-controlled Percentage of all renter-occupied units that are owned by a public housing authority

Annual rate of growth in population living in housing units Categorical variable indicating 3 consecutive monthly drops in MSA employment as computed by Regional Financial Associates, Inc.

Annual vacancy rate of rental housing (authors calculation from BLS data)

Residential Rent component of the CPI deflated by CPI-all items excluding shelter.

Gross rental space absorption (authors calculation from BLS data)

Net change in the stock of rented space (authors calculation from BLS data) 